\title{
Introduction to the special issue "Understanding social dynamics: 20 years of the swiss household panel"
}

Comprendre les dynamiques sociales: 20 ans du Panel suisse de ménages

Soziale Dynamiken verstehen: 20 Jahre Schweizer Haushalt-Panel

Robin Tillmann*, Monica Budowski**, Dean R. Lillard***, and Annette Scherpenzeel ${ }^{* * *}$

Twenty years ago, with the launch of the first Swiss Household Panel (SHP) sample, social science in Switzerland embarked on a great adventure. After having evaluated that the social sciences's development was characterized by "a number of structural deficits", Swiss researchers and institutions had to change their mindset - from the era of the lonely researcher to interdisciplinary, cooperative research Switzerland and realise that, for the social sciences, data collection, databases and data documentation centers are the functional equivalent to the laboratories and equipment the natural sciences use. The year was 1999. In 1999, in Switzerland, social science longitudinal surveys were particularly rare. It took the initiative and perseverance of visionaries to make the SHP a reality. Twenty years later, more than 2,000 researchers and students have used and continue to use SHP data. To date, those scholars have published almost 800 scientific publications; the SHP has gained an international reputation and

“... is part of a growing worldwide community of excellent researchers who analyze household panel data. These analyses make a difference in the scientific community. Many of these analyses also make a difference in local and national societies. In the future, the results of these studies will also make a difference to global society. As a member, if not a hub, of the global network of panel studies, SHP is poised to contribute significantly to science and to society." (Wagner 2018, viii)

\footnotetext{
* Swiss Center of Expertise in the Social Sciences FORS, CH-1015 Lausanne, robin.tillmann@ fors.unil.ch

** University of Fribourg, CH-1700 Fribourg, monica.budowski@unifr.ch

*** Ohio State University, OH-43201 Columbus, lillard.13@osu.edu

**** Technical University Munich, D-80333 München, scherpenzeel@mea.mpisoc.mpg.de
} 
Notwithstanding challenges such as attrition, panel studies have unique analytic advantages (see for example Duncan and Kalton 1987; Lynn 2009 or Rose 1995). According to Trivellato (1999: 340-342), panel data are essential to measure and analyse processes of mobility and inertia. More precisely, with household panel data, researchers can: (a) measure gross change; (b) distinguish between permanent and transitory characteristics of a given phenomenon; (c) study intergenerational patterns of phenomena such as poverty, income dynamics, health conditions and practices or political positioning, and (d) analyse individual development or aging as a process over time. Moreover, panel data make it possible to establish (robust) causal relationships (see for example Lieberson 1985: chapter 9). Thus, panel data are not only important for academic research, but also for monitoring and evaluating policies (see for example Piesse et al., 2009). The journal Science considers longitudinal surveys as a major area of innovation in the social sciences (Butz and Torrey 2006) and even those scholars who predict a coming crisis of empirical sociology (Savage and Burrows 2007) affirm the continuing importance of longitudinal studies.

In Switzerland, social science institutes administer most (currently running) longitudinal surveys, focusing on representative surveys at the national level. The Swiss Federal Statistical Office administers two longitudinal surveys: the Swiss Labour Force Survey that is mainly dedicated to the labour market, and the Statistics on Income and Living Conditions study (SILC) collecting data on income and living conditions. Both are rotating panels with a strong commitment to population parameter estimation. Moreover, the analytical potential of the Swiss Labour Force Survey's longitudinal component is limited because it follows respondents for only one year. The Swiss landscape of longitudinal studies includes two other types of prospective studies: four cohort panels and one household panel. The former includes the Transitions from Education to Employment survey that follows a cohort of young school leavers (from school to employment); the Survey of Health Ageing and Retirement in Europe survey that observes non-institutionalized persons aged 50 and older and their spouses/partners (independent of age); the Swiss Longitudinal Survey of Children and Youth that investigates the social conditions, experiences, and psychosocial development of children and youth; and the LIVES-FORS cohort survey, which is dedicated to a diversified sample of young adults who grew up in Switzerland. The SHP is the only (indefinite life) household panel in Switzerland. Longitudinal household data, such as the SHP, data allow the study of the life course integrating different life domains, and examining the interdependency of life courses within households. 


\section{History, design and content of the Swiss Household Panel}

\subsection{Origin and aims}

The Swiss Priority Program "Switzerland Towards the Future" implemented the SHP as one of its key structural measures in 1999 (Budowski et al. 2001). The experiences of existing European panel surveys informed the SHP's design, notably the German Socio-Economic Panel (SOEP) (Schupp and Wagner 2007) and the British Household Panel Study (BHPS), which is now integrated into Understanding Society, the UK Household Longitudinal Survey (UKHLS) (Buck and McFall 2011).

Initially, the SHP was a project jointly run by the Swiss National Science Foundation, the Swiss Federal Statistical Office, and the University of Neuchâtel. Between 2004 and 2007, the SHP developed a joint venture project "Living in Switzerland-2020" aimed at conducting a pilot study of the Statistics of Income and Living Conditions (CH-SILC) 2004-2005 survey in collaboration with the Swiss Federal Statistical Office. Since 2008, still mainly funded by the Swiss National Science Foundation, the SHP has been integrated into the Swiss Centre of Expertise in the Social Sciences (FORS) hosted by the University of Lausanne.

Two main aims guide the SHP (Farago 1996; Joye and Scherpenzeel, 1997). The first is to collect longitudinal data to complement existing cross-sectional data the Swiss Federal Statistical Office collects. In pursuit of this goal, SHP aims to create a solid database for social reporting on stability and changes in living arrangements and wellbeing in Switzerland. Indeed, the SHP is a unique longitudinal study, because it offers researchers data they can use to comprehensively analyse mid- to long-term micro-social change; other surveys in Switzerland collect data on a smaller range of topics, follow a restricted subgroup, or allow only the study of short-term transitions (see above). SHP also aims to promote opportunities for quantitative social science research by making high-quality data available to Swiss social scientists and to the international social science research community. Together with research partners in eight other countries, the SHP has, since 2008, made a subset of its data internationally comparable and distributes it as part of the CrossNational Equivalent Files (CNEF).

Household panel data have many other scientific benefits. Data collected from household panels not only allow for the estimation of gross transitions but also provide an understanding of those transitions, including the circumstances (family events, a change in the activity status, health events, etc.) causing movements in and out of a given state (for example, transitions into and out of poverty). Thus, the SHP is an important tool for fine-tuning our conceptions and analyses of social dynamics and changes across time.

The SHP features a broad range of fields and a variety of topics. These features make the SHP a valuable source of information for studies in different disciplines and allow for cross-domain analyses. To keep up with changes in the field, the SHP 
occasionally modifies the questionnaire and adds newly constructed variables to the dataset. A major criterion for any change to the questionnaire is that it should not compromise the comparability of the data over time. A second strong feature of the SHP is that it interviews all members of the households in the panel. This design allows for intra-household and intergenerational studies, such as the study of mutual influence of household members' attitudes and behaviours over time.

\subsection{Design}

The SHP's reference population includes all private households whose members represent the non-institutional resident population in Switzerland. Individuals living in old peoples' homes, institutions, or prisons, are not part of the reference population.

At present, the SHP comprises three samples: the SHP_I (7,799 individuals in 5,074 households first interviewed in 1999), the SHP_II (3,654 individuals in 2,538 households first interviewed in 2004) and the SHP_III (6,090 individuals in 3,989 households first interviewed in 2013). The household response rate in the first wave of the SHP_I, SHP_II, and SHP_III samples was 64, 65, and 60 percent respectively. Among participating households, the individual-level response rate in the first year of each sample was 85,76 , and 81 percent respectively. SHP will add a fourth sample, the SHP_IV, in 2020.

All three random samples are stratified by the seven major statistical regions of Switzerland. Within each major geographic region, each household (SHP_I and SHP_II) or individual (SHP_III) had the same inclusion probability, independent of the size of the household.

The SHP administers three questionnaires for specific purposes. The household grid questionnaire assesses household composition. The household questionnaire collects information common to all household members. The individual questionnaire collects information specific to each respondent. All household members aged 14 or older are eligible to answer the individual questionnaire. Each household has a reference person who completes the household grid and the household questionnaire. The household questionnaire also includes a questionnaire, answered by the household's reference person as proxy, that collects information on household members younger than 14 years, household members who are absent for a long period, or who are unable to respond due to illness or disability.

Based on a methodological experiment (Scherpenzeel and Eichenberger 2001), the main chosen mode of interviewing was computer-assisted telephone interviewing (CATI). Since 2010 (wave 12), CAPI and computer assisted web interview (CAWI) have been offered as alternative survey modes to those who initially refused to participate. 


\subsection{Survey content}

The household and individual questionnaires cover a broad range of topics. The questionnaires collect both 'objective' data, such as financial resources, social position, and participation, and subjective data, such as satisfaction scores, values, and attitudes. The whole constitutes an operationalisation of different elements on the micro-social level: living conditions, life events, attitudes, perceptions, and lifestyles (Budowski, et al. 1998).

The questionnaire at the household level mainly covers the following areas:

1. composition of the household: basic information (collected in the grid questionnaire) about all the members of the household, such as their age, sex, relations, nationality, level of education, and occupational status;

2. accommodation: the type and size of the accommodation, home ownership or tenancy, cost of and/or the subsidies received for housing, satisfaction with the accommodation, and evaluation of the state of the accommodation;

3. standard of living: possession of various goods such as cars, televisions or computers, and participation in various activities, such as holidays, meals at restaurants, or dentist visits, and the reasons (financial or otherwise) households do not have these goods or carry out these activities;

4. the household's financial situation: financial difficulties, indebtedness (and the reasons for it), total household income, payments to other households, expenses (e.g. for childcare), satisfaction with income, an estimate of the minimum income the household considers necessary, and an evaluation of how the household's financial situation has evolved;

5. the household and the family: external help available to the household for housework, childcare, or care for other household members, the division of housework and childcare, and decision-making within the household.

The individual questionnaires cover the following main topics:

1. the household and the family: information on children living outside the household, time spent on housework, and satisfaction with private life and the share of housework;

2. health and quality of life: general illness and health problems, doctor and hospital visits, long-term handicaps, threats or attacks endured, self-perceived state of health, estimated evolution of the state of health, satisfaction with health and with life in general, feelings of safety, tobacco consumption, and physical activities;

3. social origin (asked at first interview only): information related to each respondent's parents, including profession, professional position, educational 
level, political positioning, nationality and any financial difficulties in the family of origin (at the reference age of 15);

4. education: the respondent's native language(s), level of education completed, education currently being pursued, and participation in on-the-job training;

5. employment: information on the respondent's profession, such as working conditions, number of hours worked, work schedule, atypical work, status in the labour market, previous jobs, job satisfaction, job insecurity, and personal qualifications;

6. income: total personal income, total professional income, social security pensions, social and private transfers, and other income, plus satisfaction with the financial situation and evaluation of changes in it;

7. participation, integration, and networks: frequency of social contacts, unremunerated work outside the home, participation in associations, membership of and participation in groups, assessment of social capital by means of evaluation of potential practical help and emotional support (from various social network ties) and general trust in people;

8. politics and values: political participation, membership, party identification, political positioning, satisfaction with the political system, evaluation of issues and political values;

9. leisure and media: leisure activities, amount of leisure and holiday time, use of media, and satisfaction with leisure and free time.

10. psychological scales: (from 2009 onwards) dimensions of self-perception (such as self-mastery and self-esteem) and other aspects like the Big Five personality traits.

Since the second wave, the individual questionnaire has also included a life events module assessing the occurrence of events such as the termination of relationships, deaths of family or friends, and conflicts with relatives; and an occupational calendar module assessing (on a monthly basis) the respondent's employment situation in the twelve months prior to the interview.

In 2009 the SHP introduced a new system of modularization for the individual questionnaire. The SHP now contains three different types of questions: unique questions asked only once (usually in the first interview), core questions asked each wave and rotating core questions asked regularly (but not each year). Table 1 shows the different types of questions.

The rotating core questions are arranged in different modules, i. e. social network, religion, social participation, political behaviour and values, leisure and culture, and psychological scales. Table 2 shows the rotation calendar over the past decade. 
Table $1 \quad$ Questionnaire content

\begin{tabular}{lccc}
\hline Topics & Unique & Core & Rotating core \\
\hline Last job & $X$ & & \\
Social origin & $X$ & $X$ & \\
Socio-demographics & & $X$ & \\
Life events & $X$ & \\
Health & $X$ & \\
Education & $X$ & \\
Current job & $X$ & \\
Occupational calendar & $X$ & $X$ \\
Income & & $X$ \\
Social network & & $X$ \\
Leisure & & & $X$ \\
Social participation & & $X$ \\
Politics & & & \\
Religion & & & \\
Psychological scales & & \\
\hline
\end{tabular}

a) Last job refers to the last job held prior to entering the panel for those respondents who were not employed at the time of the first interview.

Table 2 Rotation calendar of the SHP modules from 2010 to 2020

\begin{tabular}{|c|c|c|c|c|c|c|c|c|c|c|c|}
\hline Module & 2010 & 2011 & 2012 & 2013 & 2014 & 2015 & 2016 & 2017 & 2018 & 2019 & 2020 \\
\hline $\begin{array}{l}\text { Social } \\
\text { network }\end{array}$ & $x$ & & & $x$ & & & $x$ & & & $x$ & \\
\hline Religion & & & $x$ & & & $x$ & & & $x$ & & \\
\hline $\begin{array}{l}\text { Social } \\
\text { participation }\end{array}$ & & $x$ & & & $x$ & & & $x$ & & & $x$ \\
\hline $\begin{array}{l}\text { Political be- } \\
\text { haviour and } \\
\text { values }\end{array}$ & & $x$ & & & $x$ & & & $x$ & & & $x$ \\
\hline $\begin{array}{l}\text { Leisure and } \\
\text { culture }\end{array}$ & $x$ & & & $x$ & & & $x$ & & & $x$ & \\
\hline $\begin{array}{l}\text { Psychological } \\
\text { scales }\end{array}$ & & & $x$ & & & $x$ & & & $x$ & & \\
\hline
\end{tabular}

The questionnaires used in the first wave of the SHP_III (in 2013) differed from those used in SHP_I and SHP_II. In the first wave of the SHP_III, retrospective individual biographical data were collected. In addition to the regular grid and the household questionnaire, respondents in the SHP_III sample completed a life calendar covering their entire life course starting from birth. The SHP_III life calendar is presented as a two-way grid on paper with the temporal dimension 
(in years) for the rows and various life domains in the columns (see https://www. tandfonline.com/doi/full/10.1080/21582041.2017.1418528). Respondents were asked to report events for each domain in this grid. This questionnaire has been developed with the NCCR LIVES, a Swiss National Centre of Competence dedicated to life course research. Thus, the SHP_III has an original design, combining retrospective biographical data with prospective longitudinal data.

Retrospective data also exist on a subsample of the SHP_I respondents $(\mathrm{n}=5,560)$. In 2001-2002, all SHP_I respondents were approached by mail with a self-completion questionnaire. This questionnaire collected information on education, work, and family history.

\subsection{International comparison}

The SHP was designed to allow cross-national comparisons with other household studies. In 2008, the SHP was included in the Cross-National Equivalent File (CNEF), which provides harmonized data from nine household-based panel studies (see http://cnef.ehe.osu.edu/). To date the CNEF comprises the German SocioEconomic Panel (SOEP), the UK "Understanding Society" (which includes the BHPS), the US Panel Study of Income Dynamics (PSID), the Canadian Survey of Labour and Income Dynamics (SLID), the Household Income and Labour Dynamics in Australia (HILDA), the Japan Household Panel Study (JHPS), the Korean Labor and Income Panel Study (KLIPS), the Russia Longitudinal Monitoring Survey (RLMS-HSE), and the SHP (Frick, Jenkins, Lillard, Lipps and Wooden 2007).

Panels like the SHP are in CNEF because they collect data on the same person over many years. The CNEF covers the following main topics: demographics, employment, income, and health. Because CNEF comprises longitudinal data, it affords researchers the same advantages noted above; the primary one being more powerful statistical methods to better control for otherwise unobserved person-specific heterogeneity in behaviour. But the creation of internationally comparable panel data confers an additional feature. With CNEF data, researchers can exploit policy variation across countries and over time to gain richer insights into how policies affect human behavior. Finally, researchers increasingly use CNEF to study, from a cross-national as well as a cross-disciplinary perspective, how socio-economic status is correlated and transmitted across multiple generations. The SHP is an integral CNEF member.

CNEF is a "bottom-up" standardization project. Expert social scientists standardize variables as they seek to answer specific research questions. This feature of the process involves researchers who are experts in particular topics and who, as they inform themselves of specific country institutions, bring topic-specific expertise to bear. Just as importantly, the CNEF continuously evolves as researchers refine and add to the set of harmonized variables. 
In the context of cross-national comparative work, the SHP is a motherlode of social science data. SHP is a rich resource not only because it contributes data to CNEF but also because the SHP collects data in various domains that are not yet in CNEF but that other panels also collect. For example, SHP and other panels collect data on political behaviour and values (for example, the left-right self-placement scale, interest in politics, participation in polls, and general trust in people), social participation (for example, participation in sport/leisure associations, unions, political parties or charitable organisations), leisure and culture (different items broadly comparable with those of the SOEP and the UKHLS), religion (with usual questions on religious affiliation and participation in religious services), and psychological scales (for example, the Morally Debatable Behaviour Scale, satisfaction scales, and sense of control). These data have not yet been included in CNEF. But researchers can use SHP to expand the envelope of social science knowledge. In addition, the SHP provides internationally comparable constructed variables for research in social stratification in particular (such as Treiman's prestige scale or the European Socio-Economic Classification [ESeC]).

\section{Years, and beyond}

Following a 2018 book describing how the lives of the Swiss population have changed in terms of health, family circumstances, work, political participation, and migration over the last sixteen years (see https://www.springer.com/gb/book/9783319895567), the $10^{\text {th }}$ International conference of Panel data users in Switzerland provided the opportunity to celebrate the 20 years of the SHP. Besides usual workshops, a plenary session (by Monica Budowski) entitled "20 years Swiss Household Panel: it has grown up!" looked back on the history of the SHP, and a brochure (https://forscenter.ch/ wp-content/uploads/2019/08/brochureannipsm_web.pdf) demonstrated its richness and the usefulness of longitudinal data. Based on an overview of a selection of publications by Swiss and/or foreign scholars, this brochure clearly showed major research results in social sciences and economics that would not have been possible without SHP data. Moreover, more than thirty founded Swiss National Science Foundation (SNFS) projects, including comparative projects, have been based on SHP data (according to the SNFS research database P3). Finally, figure 1 shows the increasing number of publications based on SHP data, including articles in "international" journals such as American Political Science Review, Electoral Studies, Economica, the European Journal of Political Research, European Sociological Review, International Sociology, Basic and Applied Social Psychology, Journal of Happiness Studies, Journal of Research in Personality, Sociological Methods and Research, Sociological Methodology, International Journal of Public Health, European Societies, Labour Economics, The Journal of Politics, Applied Economics, 
Social Indicators Research, and Research in Social Stratification and Mobility. Such publications significantly increase the visibility of Swiss researchers and/or those of the Swiss case within the international research community.

Figure $1 \quad$ SHP publications cumulated by type

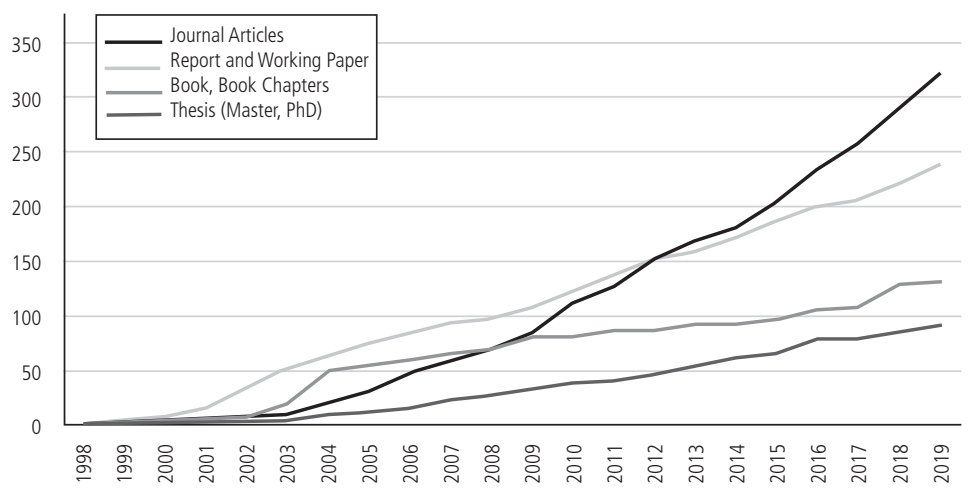

Figure 2 Round table on the future of panels

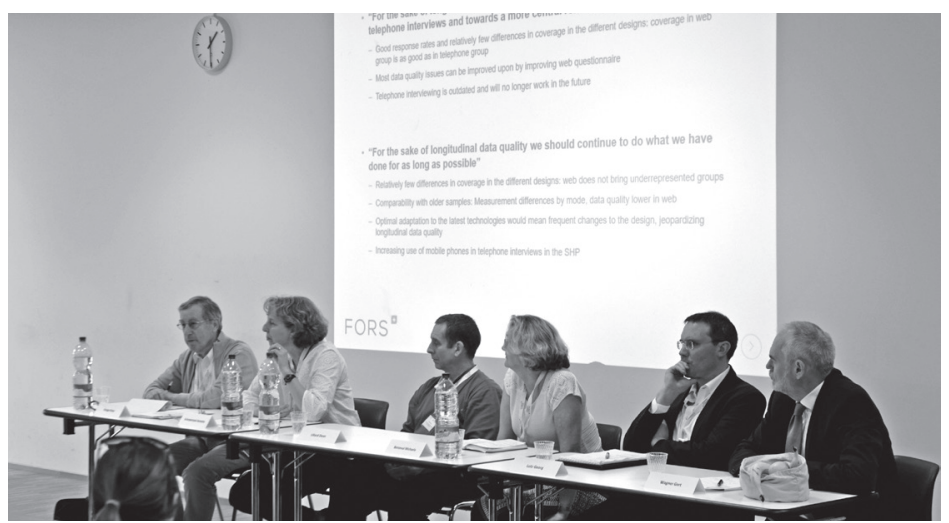

Moreover, a round table, moderated by Peter Farago, was dedicated to the "The future of households panels" with prominent scholars in the field (Michaela Benzeval, Dean Lillard, Annette Scherpenzeel, Gert Wagner), and Georg Lutz.

In this round table, three trends with regard to the future of household panel surveys were discussed: (1) the use of online and mixed modes of data collection; (2) the enrichment of survey data by linkage with register data; and (3) the challenges posed by the continuously decreasing response rates in household surveys. Firstly, 
advances in information and new communication technologies and the increasing use thereof suggest that online interviewing (CAWI), or mixed mode design including online interviewing, offer promising alternative ways of survey data collection . At the same time, such mode innovations need to first be tested thoroughly for panel studies, with respect to their effect on participation rates, selection bias, and effect on the longitudinal comparability of the data. Therefore, the SHP launched a twowave pilot study in preparation for its fourth refreshment sample, incorporating a mixed-mode experiment in 2018 and 2019. Results based on this two-wave pilot survey tend to show that the current CATI design still performs better compared to CAWI (Voorpostel et al., forthcoming). However, the costs induced by a CATI survey are much higher compared to alternative CAWI modes. Furthermore, CAWI performs quite well concerning the participation rate. However, the CAWI survey has raised some concerns regarding the quality of the data, which differs significantly from CATI and CAPI modes. The first questions generated by the results of the pilot survey concern measurement equivalence between the different modes of interviewing and the possibility to combine them. The second trend that is relevant for the future development of the SHP is the enrichment of survey data by linking it to available administrative/register data. Registers often have more accurate data than surveys on variables which are perceived as sensitive by the respondents or are difficult to answer, such as income, tax, insurance, or educational and professional trajectories. Hence, register data can be used to correct and supplement this type of survey variables, which often suffer from under- or overreporting, memory effects, and missing data caused by refusal to answer. In addition, survey questionnaires could be shortened because the variables obtained from register linkage do not have to be asked anymore. The synergies created by data linkage could thus provide the possibility to include mainly attitudinal and subjective behavioural information and reduce the length and burden of the survey.

However, a major obstacle in the use of and linkage to register data are the existing procedures and legislation of data protection, security, data access and data archiving. This difficulty is a challenge but also an opportunity: in this context, the SHP will cooperate with other surveys, in national and international perspective, to obtain a harmonised and secured mode of access for scientific researchers to register data.

The third trend that affects the future of panel surveys is the design of targeted fieldwork methods and adaptive interview modes for different groups of respondents, instead of the "one size fits all" design, as a means to combat the decreasing response rates. For example, using a shorter interview for panel members who are old or not healthy; sending different advance letters to different respondent subgroups; or using different mixed mode combinations depending on the preceding response behaviour of the panel members. The challenge of such targeted designs is to find out the reasons why different groups of panel members are less willing to participate 
than others, and to address these reasons in effective ways. The SHP can base this on the results of the pilot study experimenting with online modes of data collection and on data they have about reluctant panel members from previous panel waves. The aim of using online interviewing, mixed mode designs, and other innovation in data collection methods should be to increase willingness to participate and decrease response bias, rather than saving costs.

\section{Contributions to the special issue}

This special issue contains nine articles. The first contribution is devoted to the political consequences of social mobility in a comparative perspective (Germany and Switzerland). The originality of the paper consists of taking into account the political ideology of both the parent and their children. Hence, Van Ditmars investigates how social mobility of children affects the transmission of political ideology from parents to children, and shows that the phenomenon varies according to different types of social mobility (vertical versus horizontal). The longitudinal analyses conducted tend to show more a self-selection mechanism into social mobility than causal effects. The second paper, by Mikucka, deals with the trajectories of life satisfaction among elderly people according to different family situations, and confronts on this topic the cumulative (dis)advantage hypothesis with the age-as-leveler hypothesis. Both hypotheses seem to fail to describe such trajectories; despite this, analysis suggest that ageing without close kin does not worsen life satisfaction of elderly population (in Switzerland). In a third contribution, Lucchini and Riva analyse the effect of the work-life interface on insomnia, which is associated with various negative consequences in different fields of life. Extending prior research, they use static and dynamic methods to define the contribution of work-life conflict and psychological detachment from work to the prediction of insomnia. Among other things, the study shows that recovery and recuperation processes from/after work seem major to the experience of insomnia, contrary to perceived work-life conflict. The fourth paper, by Coste, Henchoz and Wernli, investigates the effect of various types of debt on financial satisfaction and life satisfaction. Their analyses show, in particular, that payment arrears reduce financial satisfaction more than loans or the accumulation of different types of debt. Moreover, results highlight the effect of the duration of arrears as life satisfaction impair over time with debt burdens. Three articles belong to the field of politics. The fifth contribution is dedicated to the links between subjective well-being and political participation. With this paper, Lindholm contributes to the psychological explanations of political activity. In particular, in line with earlier research, results show that subjective well-being decreases protest intentions; simultaneously, this time contrary to the expectations, analysis demonstrate no effect of subjective well-being on formal participation. The 
sixth paper, by Hadziabdic, shows that a longitudinal perspective allows solving the paradoxical lower job satisfaction of union members compared to non-members. Actually, a deterioration in job satisfaction appears to be the main reason of joining a union on the one hand. On the other hand, unions seem to be able to improve the well-being of their members after a certain number of years of membership. Voorpostel, Kuhn and Monsch examine the relationship between critical life events and support for the populist right in a seventh contribution. Thus, they show that party preference is not only shape by social class, the state of the economy or electoral campaigns but also by events in citizens' personal lives. The eighth paper, by Reveilhac and Morselli, looks at the digital shift in media consumption practices using an innovative way to exploit multiple correspondence analysis. Among other things, this contribution shows that the Swiss media space is not a dichotomous offline-online space, that the increase in online media use is firstly proper to younger cohorts, and that media consumption is cumulative. Finally, the ninth contribution, by Bornatici, Le Goff \& Gauthier, deals with the evolution of attitudes towards gender equality from 2000 to 2017. In particular, the study demonstrates that the youngest cohort surprisingly holds more traditional attitudes.

\section{References}

Buck, Nick, and Stephanie McFall. 2011. Understanding Society: design overview. Longitudinal and Life Course Studies 3(1): 5-17.

Budowski, Monica, Niklowitz, Mathias, Scherpenzeel, Annette, Tillmann, Robin, Wernli, Boris, and Erwin Zimmermann. 1998. Aims and architecture of the Swiss Household Panel. Working Paper 1. Swiss Household Panel.

Budowski, Monica, Tillmann, Robin, Zimmermann, Erwin, Wernli, Boris, Scherpenzeel, Annette, and Alexis Gabadinho, A. 2001. The Swiss Household Panel 1999-2003: Data for research on microsocial change. ZUMA-Nachrichten 50: 100-125.

Butz William P., and Barbara Boyle Torrey. 2006. Some Frontiers in Social Science. Science 312 (5782): 1898-1900.

Duncan, Greg J., and Graham Kalton. 1987. Issues of Design and Analysis of Surveys Across Time. International Statistical Review 55(1): 97-117.

Farago, Peter. 1996. Gesellschaftliche dauerbeobachtung im SP "Zukunft Schweiz/Demain la Suisse” [Swiss Priority Programme "Switzerland towards the future"]. Swiss National Science Foundation.

Frick, Joachim R., Jenkins, Stephen P., Lillard, Dean R., Lipps, Oliver, and Mark Wooden. 2007. The Cross-National Equivalent File (CNEF) and its member country household panel studies. Schmollers Jahrbuch 127(4): 627-654.

Joye, Dominique, and Annette Scherpenzeel. 1997. Observation à long terme: Projet de panel. Programme Prioritaire Demain la Suisse. Swiss National Science Foundation.

Lieberson, Stanley. 1985. Making It Count: The Improvement of Social Research and Theory. Berkeley: University of California Press.

Lynn, Peter. 2009. Methods for Longitudinal Surveys. Pp. 1-19 in Methodology of Longitudinal Surveys, edited by Peter Lynn. Chichester: Wiley. 
Piesse, Andrea, David Judkins, and Graham Kalton. 2009. Using Longitudinal Surveys to Evaluate Interventions. Pp. 303-316 in Methodology of Longitudinal Surveys, edited by Peter Lynn. Chichester: Wiley.

Rose, David. 1995. Household Panel Studies: an Overview. Innovation 8(1):7-24.

Savage, Mike and Roger Burrows. 2007. The Coming Crisis of Empirical Sociology. Sociology 41(5):885899.

Scherpenzeel, Annette and Philippe Eichenberger. 2001. Mode effects in panel surveys:A comparison of CAPI and CATI. Neuchâtel: Federal Statistical Office.

Schupp, Jürgen, and Gert G. Wagner. 2007. The German Socio-Economic Panel Study (SOEP): Scope, evolution and enhancements. Schmollers Jahrbuch 127(1): 139-169.

Trivellato, Ugo. 1999. Issues in the Design and Analysis of Panel Studies: A Cursory Review. Quality \& Quantity 33(3): 339-352.

Voorpostel, Marieke, Lipps, Oliver, and Caroline Roberts. Forthcoming. Mixing modes in panel surveys: recent developments and new findings. In: Peter Lynn (Ed.) Advances in Longitudinal Survey Methodology. Chichester: Wiley.

Wagner, Gert G. 2018. Preface. Pp.vii-viii in Social Dynamics in Swiss Society: Empirical Studies Based on the Swiss Household Panel, edited by Robin Tillmann, Marieke Voorpostel, and Peter Farago. Cham: Springer. 